\title{
Modeling Analysis of the Upper Limit Water Level Mechanism in the Upstream Reservoir of a Dam Embankment
}

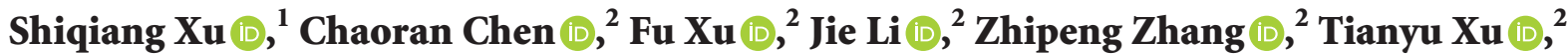 \\ and Linxuan $\mathrm{Zhu}^{2}{ }^{2}$ \\ ${ }^{1}$ School of Science, Chang'an University, Xi'an, Shaanxi 710064, China \\ ${ }^{2}$ School of Highway, Chang'an University, Xi'an, Shaanxi 710064, China \\ Correspondence should be addressed to Shiqiang Xu; xsq005596@chd.edu.cn and Chaoran Chen; chenchaoran@chd.edu.cn
}

Received 7 July 2020; Revised 10 November 2020; Accepted 13 November 2020; Published 29 November 2020

Academic Editor: Liborio Cavaleri

Copyright (C) 2020 Shiqiang Xu et al. This is an open access article distributed under the Creative Commons Attribution License, which permits unrestricted use, distribution, and reproduction in any medium, provided the original work is properly cited.

\begin{abstract}
The dam embankment (DE) is a highway structure used in the Loess Plateau to integrate the functions of a highway embankment and a dam. This paper studies the upper limit water level mechanism of the reservoir in the upstream of the DE to determine the criterion for setting upper culverts on the DE. A reservoir model is first established, and then the replenishment and loss of the reservoir water is simulated. The principle of water balance is employed to obtain water level formulas for the reservoir. Finally, an engineering example is used to verify the upper limit water level mechanism. The results show that the water level of the reservoir fluctuates near an ideal balance water level and an upper limit water level exists. Moreover, the upper limit water level has no relation to the water storage time, and is only related to the reservoir shape with big upper and small bottom, the small amount of water entering the reservoir each year, and the large water loss caused by evaporation and leakage. The upper culvert setting criterion is obtained through the upper limit water level mechanism, and it will provide important reference significance for the necessity of the DE culvert setting.
\end{abstract}

\section{Introduction}

The active development of China's economy has stimulated a growth in the number of highways being constructed in the Loess Plateau. Located in the north-central part of China, the Loess Plateau has an area of approximately $640,000 \mathrm{~km}^{2}$. The region is characterized by continuous Quaternary silty loess deposits of 50-300 $\mathrm{m}$ in thickness, with few rocky mountain areas in the plateau where the loess thickness is less than $50 \mathrm{~m}$ [1]. Dissected by deep gullies, the altitude of the plateau is $1000-2000 \mathrm{~m}$, with a relative relief of 100-300 $\mathrm{m}$ [2]. The length of the gullies and ravines is greater than $3-4 \mathrm{~km} / \mathrm{km}^{2}$, with a maximum length of over $10 \mathrm{~km} / \mathrm{km}^{2}$ [3]. Water scarcity is also a serious problem in this region. The Loess Plateau belongs to the semiarid continental monsoon climate zone, with an average annual precipitation of $150-750 \mathrm{~mm}$ and annual evaporation of 1400-2000 mm [4]. Due to these conditions, the area experiences serious soil erosion and is one of the most fragile ecological environments in the world [5].
The construction of roads in such areas will inevitably produce a large number of high embankments, and research into the high embankment culverts is essential as construction develops further in the area. Culverts have traditionally been located at the bottom of the embankment to immediately remove water from the highway. However, the culverts are easily damaged and maintenance costs are high. To reduce these costs and store water resources, engineers in the Loess Plateau now set culverts on the upper part of the embankment to create dam embankments (DEs) based on check dam construction. The study area and a typical DE are illustrated in Figure 1. Check dams are the most widely applied engineering structures for soil and water conservation in erodible regions, and have been used for over 400 years in China $[6,7]$. The implementation of check dams for soil erosion control has also been reported in other countries including the United States, India, France, Italy, Ethiopia, Mexico, and Spain [8-10]. A check dam is usually composed of three parts: the embankment, the spillway, and the outlet, while simple check dams are occasionally constructed 


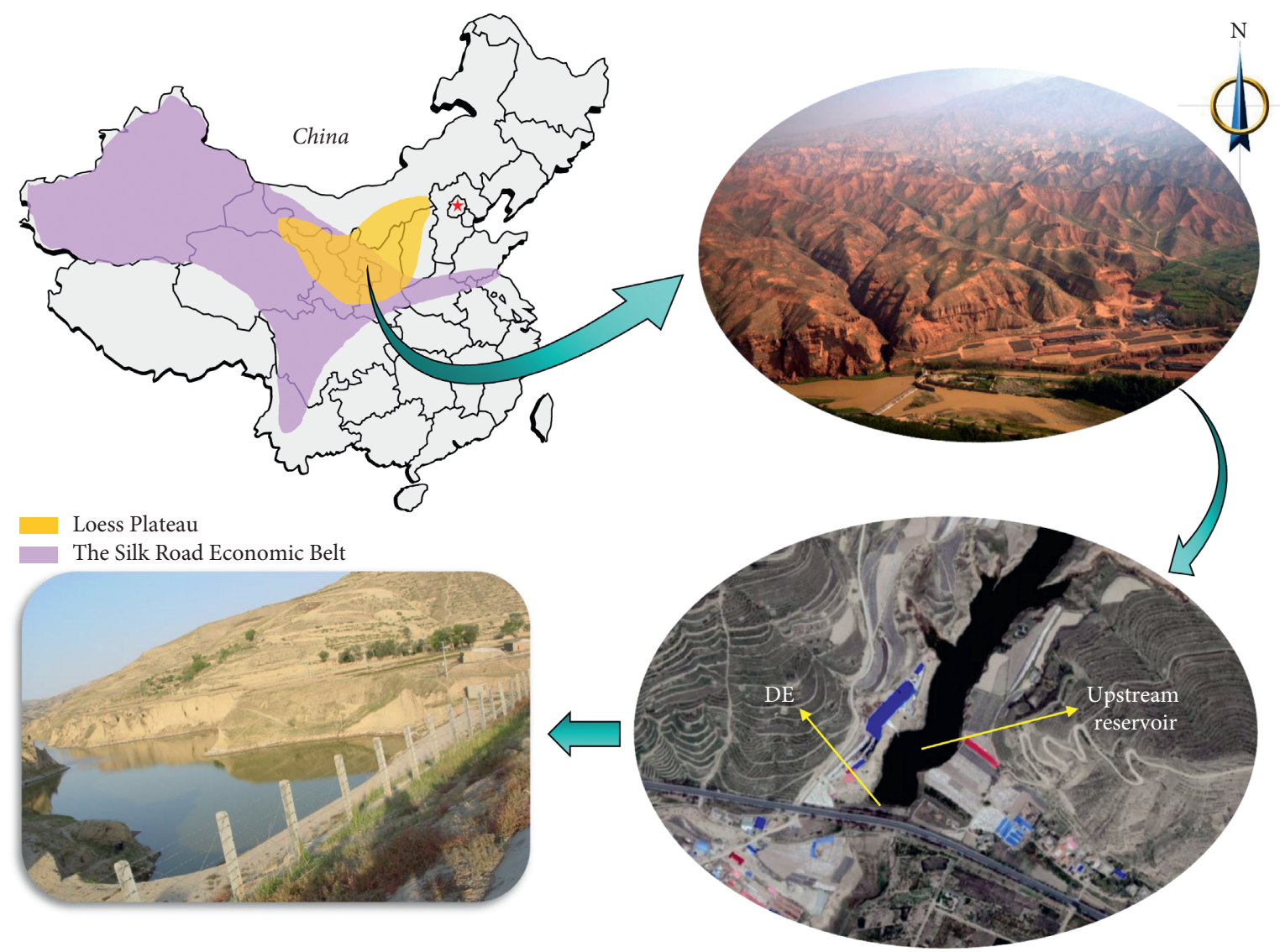

FIgure 1: Study area and a typical DE.

without spillways or outlets [11]. A DE mainly consists of two components: the embankment and the upper culvert (Figure 2). The four main functions of the DE are reduced construction costs for a shorter culvert, lower maintenance costs, conservation of water resources, and minimizing soil and water loss.

Nearly 100 DEs have been built in Gansu Province on the Loess Plateau since the 1990s. Due to significant social and environmental advantages, DE is regarded as an environmentally friendly road construction method by local authorities. However, due to low rainfall, a small catchment area, and rapid evaporation, the upper culvert's drainage function is not fully exerted in these embankments, and in most cases, it is not functional at all. According to a survey of the majority of DEs that have been in operation for some years in Gansu Province in 2016, a large majority of the upper culverts were idle. As a result, engineers and designers have questioned the necessity of constructing the upper culverts. As there is no reliable research or existing calculation methods available, the issue remains unresolved.

Previous studies on culverts of high embankments mainly focus on the earth pressure of culverts [12-15], the performance of various types of culverts [16-19], and their dynamic response [20-23]. However, the culverts of the DE are located at the upper part of the embankment, and few studies have explored the flood discharge capacity of DE culverts. Current relevant regulations only focus on the

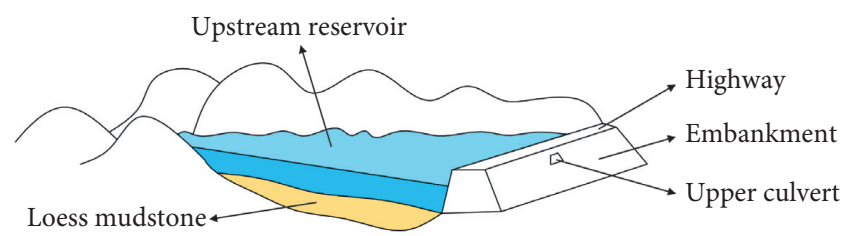

FIGURE 2: Dam embankment and its upstream reservoir.

design of common culverts, excluding the design of DE culverts $[24,25]$. This lack of regulation in the design process can cause these culverts to be idle for two decades or longer in some cases due to inadequate design. Therefore, it is necessary to study the setting conditions of the upper culverts.

Gao et al. used the water storage increment method to conduct a hydrological analysis on the design of DE culverts [26]. They gave the determination methods for the culvert construction exemption, postponement and construction at the same time as the DE. However, the upstream reservoir of the DE is assumed to be a frustum of a cone, and it is assumed that the annual water inflow enters the reservoir once at the beginning of the calculation. Due to the big difference between the frustum of a cone and the actual reservoir shape, and the fact that the annual water inflow entered the reservoir at one time was not in accordance with the actual situation, they finally failed to obtain the upper limit water level mechanism. However, this study provides ideas for 
further research. $\mathrm{Xu}$ et al. established a reservoir model for the geometric boundary conditions of the U-shaped gully upstream of the DE [27]. They proposed that the upstream reservoir of DE without drainage has normal upper limit water level under the condition of normal annual rainfall inflow without considering the influence of sediment. They believe that the reason why the culvert is idle is that the upper limit water level is lower than the bottom elevation of the culvert. It is worth noting that the paper does not consider the influence of floods with different return periods on the conclusion, and there is a certain difference between the U-shaped gully and the actual loess gully. The mechanism of upper limit water level is still not obtained. In order to further study this issue, some scholars introduced the flood limit water level in water conservancy into the design of improving the flood discharge capacity of the upper culvert [28]. They think that the design of culvert flood discharge force can be improved by treating the upper limit water level as the flood limit water level of the upstream reservoir of DE and that the flood limit water level of the reservoir is the key to solve the problem of excessive flood discharge force of the culvert. In the end, this study failed to obtain the upper limit water level mechanism and the appropriate setting conditions for the upper culverts. In subsequent research, other scholars proposed to establish a water level-storage capacity relationship curve to determine the flood limit water level, and use the flood regulation formula to determine the criteria for setting upper culverts [29]. They mainly used the method of dealing with reservoir shape and storage capacity in water conservancy to give the judgment conditions of the DE culverts setting. Due to the need to adopt comprehensive parameters for water level calculation and adjustment, it is difficult to combine with the actual situation. There are many similarities between check dams and DEs in some aspects. When calculating the upstream storage capacity of check dams, some studies have adopted the trapezoidal gully model consistent with this paper, and obtained better results [30-32].

DEs can be considered as small dams on the other hand, so it is necessary to consider flood events caused by extreme weather or earthquakes when calculating water levels $[33,34]$. The influence of frequency floods on the research results is fully considered in this work. The disasters caused by dam break are also worthy of our attention [35]. Because DEs are usually built in remote loess gully areas, far away from communities and farmland, coupled with small water storage, the disasters caused are limited.

The current research mainly focuses on when the DE culverts will be built. This work focuses on the necessity of the DE culverts setting. The ultimate purpose of this study is to provide the relevant designers with a basis for judging whether the culverts is set or not. This work will study the upper limit water level mechanism in the upstream reservoir of a DE by establishing a reservoir model. Through the mechanism of upper limit water level, this paper will discuss the setting conditions of the upper culverts on the DE.

In this work, a reservoir model is first established, and reservoir replenishment and loss patterns are simulated. Water level formulas are further derived with the theory of seepage and evaporation and the principle of water balance. Finally, the upper limit water level mechanism of the upstream reservoir of the $\mathrm{DE}$ is verified by engineering examples. A frequency flood calculation was performed on the upstream reservoir to study the overtopping risk of the embankment and the impact of frequency flood on the upper limit water level mechanism. The flood detention capacity is further obtained from the upper limit water level. By comparing the flood detention capacity with the total amount of frequency flood, the setting criterion of the upper culverts is obtained.

\section{Model}

2.1. Reservoir Model. Basic characteristics of the DE and its upstream reservoir (gully) were obtained through field investigation and data analysis in this study. The upper culvert is located in the upper part of the DE. However, in order to study the fluctuation of the water level in the upstream reservoir of DE and the setting conditions of the upper culvert, the upper culvert was removed and the height of the $\mathrm{DE}$ is assumed to be unlimited. The DE slope is protected with waterproof geotextile (asphalt glass cloth), and the dam foundation leakage and the seepage around the dam are ignored. The gully has a large upper and a small bottom, and the bottom of the gully is a longitudinal slope which is usually an impermeable layer of viscous mudstone. Both sides of the gully are homogeneous natural loess. The annual sediment deposition accounts for about $1-3 \%$ of the annual inflow, so the influence of sediment deposition on the upstream reservoir storage was neglected [26]. In summary, the following assumptions are established for constructing the reservoir model:

(1) The height of DE is unlimited, the upstream reservoir is closed, and there are no outlets

(2) The cross section of the gully is a trapezoid

(3) The influence of sediment deposition on upstream reservoirs storage is neglected

Before the establishment of the model, the expansion method is used to straighten the reservoir area longitudinally to ensure that the storage volume is basically unchanged. The reservoir model is illustrated in Figure 3.

The water surface area $A(h)$ at height $h$ for the model can be expressed as

$$
A(h)=h \cot (\alpha)(W+2 h \cot (\beta))
$$

where $\alpha$ is the angle between the longitudinal slope of the gully bottom and the horizontal plane, $W$ is the width of the gully bottom, and $\beta$ is the slope on both sides of the gully.

Therefore, the reservoir capacity $Q(h)$ at the water level $h$ can be expressed as

$$
Q(h)=\int_{0}^{h} A(h) \mathrm{d} h=\frac{1}{2} \cot (\alpha) W h^{2}+\frac{2}{3} \cot (\alpha) \cot (\beta) h^{3} .
$$

A formula for calculating reservoir leakage amounts is provided in [36]: 


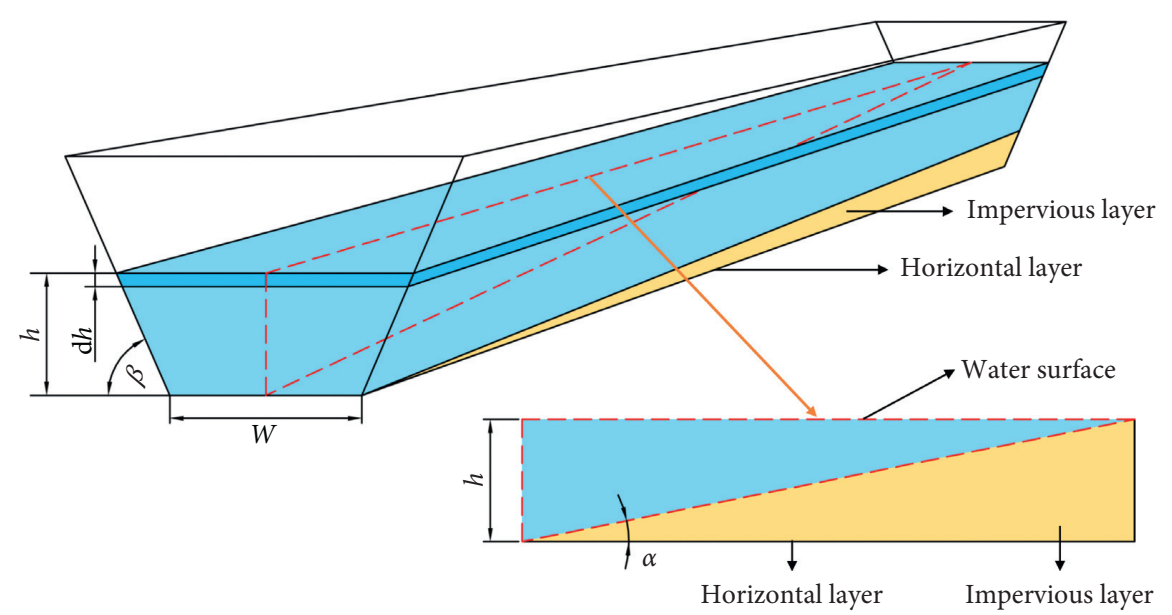

FIgURe 3: Reservoir model.

$$
q=\frac{K}{2 L}\left(y_{p}^{2}-h_{p}^{2}\right)
$$

where $q$ is the leakage of a single-width section of watershed, $K$ is the permeability coefficient, $L$ is the average seepage path, $y_{p}$ is the reservoir water level, and $h_{p}$ is the adjacent valley water level. From an engineering practice perspective, simplifying the calculation requires considering that $K$ is constant and the seepage flow belongs to stable flow. Figure 4 shows the meaning of related geometric quantities.

In most cases, adjacent valleys are dried up; that is, $h_{p}$ is equal to 0 . Equation (3) is then simplified as

$$
q=\frac{K}{2 L} y_{P}^{2}
$$

Therefore, leakage $Q_{L 0}$ per unit time of the reservoir at height $h$ can be expressed as

$$
Q_{L 0}=q_{L} S_{L}+q_{R} S_{R}=\left(\frac{K_{L}}{2 L_{L}}+\frac{K_{R}}{2 L_{R}}\right) h^{3} \cot (\alpha)
$$

where $q_{L}$ is the leakage of a single-width section on the left bank and $q_{R}$ is the leakage on the right bank, $S_{L}$ is the left bank length and $S_{R}$ is the right bank length, $K_{L}$ is the left bank permeability coefficient and $K_{R}$ is the right bank permeability coefficient, and $L_{L}$ is the average seepage path of the left bank and $L_{R}$ is that of the right bank.

According to equation (1), unit time evaporation $Q_{E 0}$ of the reservoir at height $h$ is expressed as

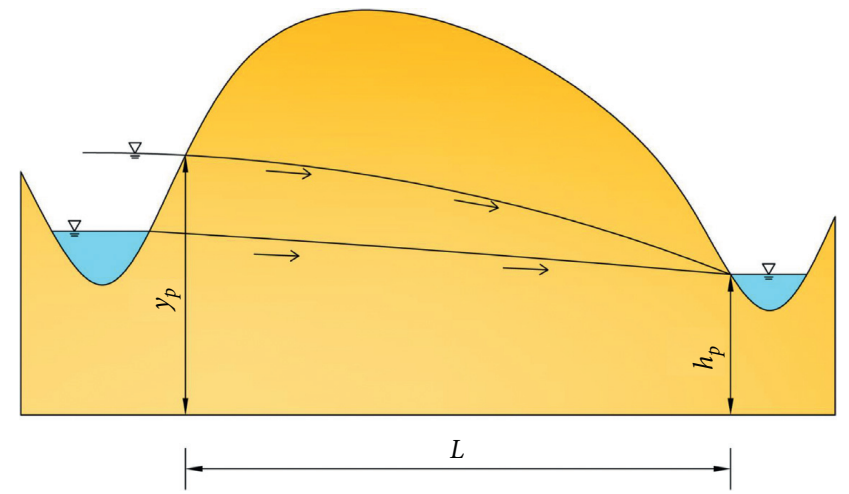

FIGURE 4: Schematic diagram of reservoir leakage.

$$
Q_{E 0}=A(h)\left(0.8 E_{w}-E_{l}\right)=h \cot (\alpha)(W+2 h \cot (\beta))\left(0.8 E_{w}-E_{l}\right),
$$

where 0.8 is the water surface evaporator conversion coefficient, $E_{w}$ is the annual average water surface evaporation and its unit is $\mathrm{mm} \cdot \mathrm{a}^{-1}$, and $E_{l}$ is the annual average land evaporation and its unit is $\mathrm{mm} \cdot \mathrm{a}^{-1}$. As well, $E_{l}$ is equal to the annual average rainfall minus the annual average runoff depth.

According to equations (5) and (6), the total reservoir water loss rate at height $h$ is equal to the sum of leakage rate and evaporation rate; that is,

$$
f(h)=\left(\frac{K_{L}}{2 L_{L}}+\frac{K_{R}}{2 L_{R}}\right) h^{3} \cot (\alpha)+h \cot (\alpha)(W+2 h \cot (\beta))\left(0.8 E_{w}-E_{l}\right)
$$

2.2. Reservoir Water Replenishment and Loss. The supplementary source of the upstream reservoir of the DE is only rainwater. The reservoir water supplement is composed of reservoir surface rainfall and rainfall runoff. As the influencing factors such as catchment area, rainfall level, and vegetation are complex, the amount of supplemental inflow water varies annually [37]. This paper focuses on the upper limit water level mechanism and the setting conditions of the upper culverts. The main idea of this paper does not involve the calculation of the annual inflow of the reservoir. The 
annual water inflow is selected from results with consideration of the most unfavorable situation. The annual water inflow volume is also assumed to be constant.

Annual water inflow is determined; however, thousands of ways exist for the annual inflow to flow to the reservoir. To describe reservoir replenishment and loss patterns quantitatively, the reservoir water supplement can be divided into two categories, instantaneous inflow and continuous uniform inflow, according to the supplementary occupation time length. Instantaneous inflow does not take time to enter the reservoir and simulates sudden runoff caused by heavy rain and the reservoir surface rainstorm supplement. In this case, evaporation and leakage do not have time to occur or the amount of loss is minimal. Continuous uniform inflow takes time to enter the reservoir, simulating the slow and continuous inflow of runoff caused by continuous rainfall and the continuous supplementary rainfall on the reservoir surface. In this case, the loss by evaporation and leakage during the period cannot be ignored. The actual water replenishment process can be further divided into many instantaneous inflows and continuous uniform inflows. The established reservoir water replenishment and loss mode is illustrated in Figure 5. The reservoir is in a dry state without water supplement, and leakage exists throughout the year.

The spatial and temporal distribution of rainfall varies widely $[38,39]$, resulting in a constantly evolving reservoir water replenishment and loss model. In fact, the actual replenishment and loss of the reservoir can be expressed according to Figure 5(a). As shown in Figure 5, using the limit method, two extreme conditions (Figures 5(b) and 5(c)) are present in the reservoir water replenishment and loss model. According to the understanding of local precipitation characteristics, three intermediate working conditions (Figures 5(d)-5(f)) were obtained. The first extreme condition is an instantaneous inflow in extreme conditions, as shown in Figure 5(b). In this case, the annual total water inflow enters the reservoir at once, and this occurs annually. Obviously, this kind of condition has the largest amount of supplement and the longest drought time, so the difference between the highest water level and the lowest water level varies the most, and the fluctuation of water level is the greatest during the year. The second extreme condition is continuous inflow in extreme conditions, as shown in Figure 5(c). In this case, the annual total water inflow continues to flow evenly into the reservoir, as it does in subsequent years. The ideal balance water level can then be obtained, which is the water level when the average replenishment rate and the average loss rate reach a dynamic balance. Intermediate working conditions occur between the two extreme conditions.

In fact, the real replenishment and loss patterns of the reservoir are close to intermediate conditions. There is a certain gap between the water supplement and loss mode of the reservoir described in Figure 5 and the actual situation. The DEs studied in this paper were located in Gansu Province. According to the local rainfall data, the flood season and dry season can be observed as distinct. The flood season occurs from May to September, and the remaining months are the dry season. The rainfall in flood season accounts for more than $80 \%$ of the annual rainfall, as shown in Figure 6. Based on the above situation, three intermediate conditions are determined:

(1) Two instantaneous inflows, as shown in Figure 5(d): each supplemental water inflow accounts for half of the total annual water inflow. The supplement occurs at the beginning and end of the rainy season and the drought lasts for seven months.

(2) One continuous uniform inflow, as shown in Figure 5(e): continuous uniform inflow lasts for five months.

(3) Mixed inflow, as shown in Figure 5(f): There are two instantaneous inflows and one continuous uniform inflow. Each supplemental water inflow accounts for $1 / 3$ of the total annual water inflow.

\subsection{Water Level Calculation Formula}

2.3.1. Ideal Balance Water Level. As shown in Figure 5(c), the annual water inflow is continuously and evenly replenished to the reservoir, and evaporation and leakage exist throughout the year. When the average replenishment rate of the reservoir is equal to the average loss rate, the ideal balance water level can be obtained. The annual total water volume is evenly added to the reservoir. Using equation (7), the ideal balance water level can be obtained:

$$
\left(\frac{K_{L}}{2 L_{L}}+\frac{K_{R}}{2 L_{R}}\right) h^{3} \cot (\alpha)+\frac{h \cot (\alpha)(W+2 h \cot (\beta))\left(0.8 E_{w}-E_{l}\right)}{365}=\frac{Q_{a}}{365},
$$

where $Q_{a}$ is the total amount of water entering the reservoir each year and its unit is $\mathrm{m}^{3} \cdot \mathrm{a}^{-1}$.
2.3.2. General Formula of Water Level. Using equation (7) and defining $B=\left(K_{L} / 2 L_{L}\right)+\left(K_{R} / 2 L_{R}\right)$, when the water 


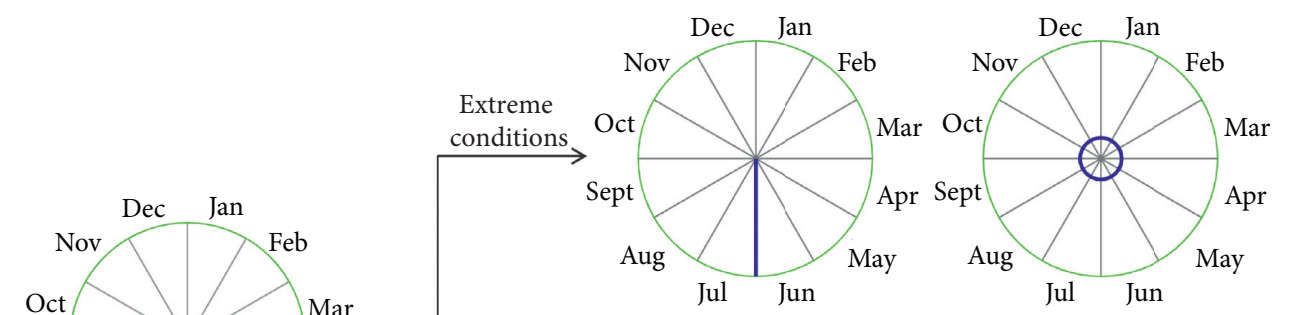

(b)

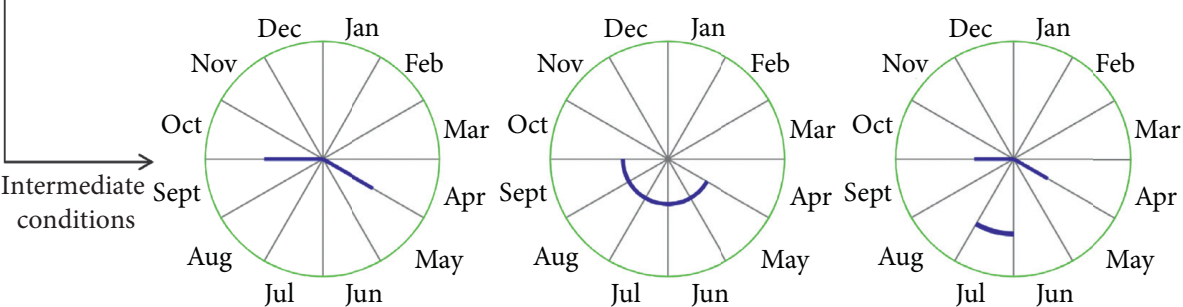

(d) (f)

The blue straight line represents instantaneous inflow, and its length represents the amount of water inflow. The blue arc represents continuous uniform inflow, and its length represents the amount of water inflow. In each of the small figure, the total length of the blue line is constant.

Figure 5: (a) Mode of reservoir water replenishment and loss; (b) an instantaneous inflow in extreme conditions; (c) continuous inflow in extreme conditions; (d) two instantaneous inflows in intermediate conditions; (e) one continuous inflow in intermediate conditions; (f) mixed inflow in intermediate conditions.

level rises from $h_{1}$ to $h_{2}$ uniformly, the average reservoir water loss rate $\overline{f(h)}$ is

$$
\begin{aligned}
\overline{f(h)} & =\frac{1}{h_{2}-h_{1}} \int_{h_{1}}^{h_{2}} f(h) \mathrm{d} h=\frac{B \cot (\alpha)}{4}\left(h_{1}^{2}+h_{2}^{2}\right)\left(h_{1}+h_{2}\right)+\frac{2}{3} \cot (\alpha) \cot (\beta)\left(0.8 E_{w}-E_{l}\right)\left(h_{1}^{2}+h_{1} h_{2}+h_{2}^{2}\right) \\
& +W\left(0.8 E_{w}-E_{l}\right) \frac{\cot (\alpha)}{2}\left(h_{1}+h_{2}\right) .
\end{aligned}
$$

Next, according to equation (2), when the water level rises from $h_{1}$ to $h_{2}$, the reservoir capacity changes $Q_{\Delta h}$ are determined as follows:

$$
Q_{\Delta h}=\frac{1}{2} \cot (\alpha) W\left(h_{2}^{2}-h_{1}^{2}\right)+\frac{2}{3} \cot (\alpha) \cot (\beta)\left(h_{2}^{3}-h_{1}^{3}\right) .
$$

Finally, the principle of water balance is employed. In $\Delta t$ time, the amount of leakage and evaporation loss plus the change in storage capacity is equal to the amount of water entering the reservoir within $\Delta t$ time. Thus, the general formula of the water level is derived as

$$
\overline{f(h)} \Delta t+Q_{\Delta h}=Q_{\Delta t},
$$

where $Q_{\Delta t}$ is the amount of water entering the reservoir within a period of time $(\Delta t)$.

2.3.3. Low Water Level. Using equation (11), when it is dry at $\Delta t$ time and the water level is lowered from high water level $h_{2}$ to low water level $h_{1}$, assuming that the water level drops at a constant speed, the loss of reservoir water quantity is equal to the change of storage capacity:

$$
\overline{f(h)} \Delta t=Q_{\Delta h} .
$$

Substituting equations (9) and (10) into the above formula, and defining $C_{1}=-8 \cot (\beta)-3 B \Delta t, C_{2}=-6 \mathrm{~W}-$ $3 B \Delta t h_{2}-8 \Delta t \cot (\beta)\left(0.8 E_{w}-E_{l}\right), \quad C_{3}=-6 \Delta t W \tau-3 B \Delta t$ $h_{2}^{2}-8 \Delta t h_{2} \cot (\beta)\left(0.8 E_{w}-E_{l}\right)$, and $C_{4}=6 W h_{2}^{2}+8 \cot$ $(\beta) h_{2}^{3}-3 B \Delta t h_{2}^{3}-8 \Delta t h_{2}^{2} \cot (\beta)\left(0.8 E_{w}-E_{l}\right)-6 \Delta t h_{2} W(0.8$ $E_{w}-E_{l}$ ), equation (12) can be transformed into

$$
C_{1} h_{1}^{3}+C_{2} h_{1}^{2}+C_{3} h_{1}+C_{4}=0 .
$$

Equation (13) is a formula for calculating the low water level $h_{1}$ when it is dry at $\Delta t$ time.

2.3.4. High Water Level. High water level is divided into two cases, high water level when instantaneous inflow is entering the reservoir and high water level when continuous uniform inflow is entering the reservoir. When instantaneous inflow 


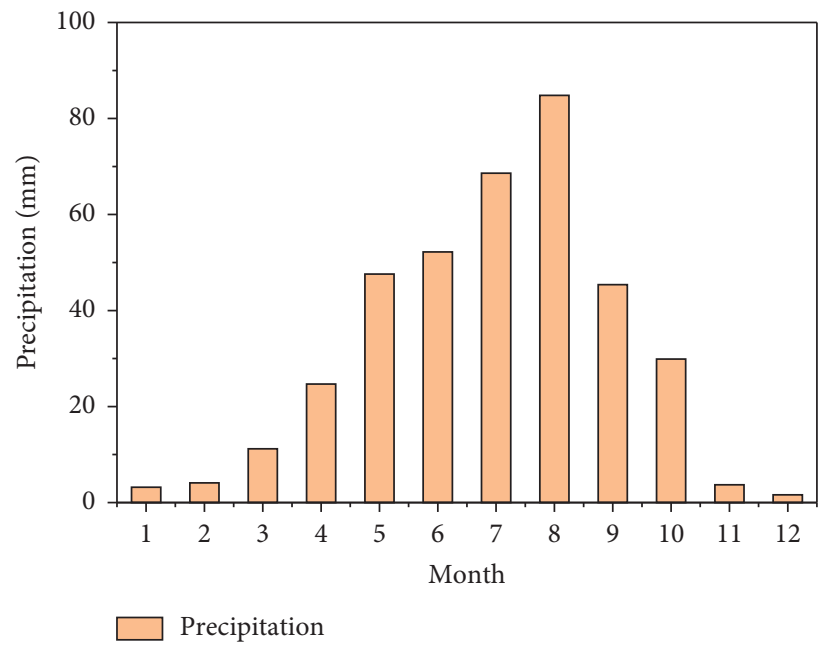

FIGURE 6: Distribution of monthly average precipitation in the study area from 1981 to 2016.

enters into the reservoir, it takes very little time; that is, $\Delta t=0$, and evaporation and leakage cannot occur. The amount of water entering the reservoir only causes changes in the storage capacity. As the water level rises from $h_{1}$ to $h_{2}$, equation (11) becomes

$$
Q_{\Delta h}=Q_{\Delta t}
$$

Substituting equation (10) into the above formula, and defining $D_{1}=4 \cot (\alpha) \cot (\beta), \quad D_{2}=3 \cot (\alpha) W, \quad$ and $D_{4}=-4 \cot (\alpha) \cot (\beta) h_{1}^{3}-3 \cot (\alpha) W h_{1}^{2}-6 Q_{\Delta t}$, equation (14) is then transformed into

$$
D_{1} h_{2}^{3}+D_{2} h_{2}^{2}+D_{4}=0
$$

Equation (15) can be used to calculate the high water level $h_{1}$ when instantaneous inflow is entering the reservoir.

When the continuous uniform inflow enters the reservoir in $\Delta t$ time, the water level rises from low level $h_{1}$ to high level $h_{2}$. The total loss of the reservoir plus the variation of the reservoir water amount is equal to the amount of water entering the reservoir in $t$ time. Substituting equations (9) and (10) into equation (11), and defining $E_{1}=B \cot (\alpha) \Delta t / 4$, $E_{2}=2 \cot (\alpha) \cot (\beta)\left(0.8 E_{w}-E_{l}\right) \Delta t / 3, \quad E_{3}=W \cot (\alpha)$ $\left(0.8 E_{w}-E_{l}\right) \Delta t / 2, \quad E_{4}=W \cot (\alpha) / 2, \quad$ and $\quad E_{5}=2 \cot (\alpha)$ $\cot (\beta) / 3, E_{6}=Q_{\Delta t}$, then $F_{1}=E_{1}+E_{5}, F_{2}=E_{1} h_{1}+E_{2}+E_{4}$, $F_{3}=E_{1} h_{1}^{2}+E_{2} h_{1}+E_{3}$ and $F_{4}=E_{1} h_{1}^{3}+E_{2} h_{1}^{2}+E_{3} h_{1}-$ $E_{4} h_{1}^{2}-E_{5} h_{1}^{3}-E_{6}$, and equation (11) can be converted to

$$
F_{1} h_{2}^{3}+F_{2} h_{2}^{2}+F_{3} h_{2}+F_{4}=0 \text {. }
$$

Equation (16) can be used to calculate the high water level $h_{2}$ when the continuous uniform inflow enters the reservoir in $\Delta t$ time.

\section{Example Calculation}

3.1. Parameter Value. A large number of DEs have been built on the G109 line, G310 line, G312 line, and other roads in
Gansu Province, and most of which cross trapezoidal gullies. Among them, there are few DEs with good water storage. The DE of G310 line with the stake number of $\mathrm{K} 168+740 \sim \mathrm{K} 168+880$ was chosen as the engineering example for water level check calculation in this study, and its upstream reservoir has good water storage. After surveying the embankment, it was found that the DE slope is protected with waterproof geotextile (asphalt glass cloth). The average longitudinal slope of the gully ditch is about $2 \%$, and the slopes on both sides of the gully are natural loess. The water level at the time of measurement was $11.74 \mathrm{~m}$. The highest water level was determined by the retention height of floating matter on the water surface and through communication with local villagers, and is $1.13 \mathrm{~m}$ higher than the measured water level at the time. The DE data are provided in Table 1.

Based on the measured results and local meteorological data, the DE parameters are shown in Table 2. Ew and El come from local meteorological data. The annual water inflow of the reservoir was selected from existing research [29]. This value takes into account the local rainfall over the past 50 years. This value is the normal annual inflow maximum of the reservoir with consideration of the most unfavorable situation. It was also assumed that the annual water inflow volume is constant.

3.2. Calculation Results. The initial water level for each working condition is 0 , and the data in Table 2 are substituted into equation (8) to obtain the ideal balance water level. The low water level is calculated using equation (13), and the high water level is calculated using equations (15) and (16). The calculation results of the various working conditions are shown in Figures 7-11.

It can be concluded from Figures $7-11$ that when the total amount of water entering the reservoir is fixed every year, the high water level and the low water level will rise with the increase of water storage time. After a certain period of time, the high water level and the low water level fluctuate up and down in the ideal balance water level, and the high 
TABle 1: Data of DE at G310 highway.

\begin{tabular}{lcccccc}
\hline $\begin{array}{l}\text { Highway } \\
\text { name }\end{array}$ & Highway grade & $\begin{array}{c}\text { Year of } \\
\text { completion }\end{array}$ & $\begin{array}{c}\text { Year of starting } \\
\text { storage }\end{array}$ & $\begin{array}{c}\text { Catchment area } \\
\left(\mathrm{km}^{2}\right)\end{array}$ & $\begin{array}{c}\text { Highest historical water } \\
\text { level }(\mathrm{m})\end{array}$ & $\begin{array}{c}\text { Culvert bottom } \\
\text { height }(\mathrm{m})\end{array}$ \\
\hline G310 & $\begin{array}{c}\text { Second-class } \\
\text { highway }\end{array}$ & 2002 & 1998 & 2.3 & 12.87 & 18.40 \\
\hline
\end{tabular}

TABLE 2: Calculation parameters.

\begin{tabular}{lcccccccccc}
\hline Parameter & $\alpha\left(^{\circ}\right)$ & $\beta\left(^{\circ}\right)$ & $K_{L}\left(\mathrm{~cm} \cdot \mathrm{s}^{-1}\right)$ & $K_{R}\left(\mathrm{~cm} \cdot \mathrm{s}^{-1}\right)$ & $L_{L}(\mathrm{~m})$ & $L_{R}(\mathrm{~m})$ & $W(\mathrm{~m})$ & $E_{w}\left(\mathrm{~mm} \cdot \mathrm{a}^{-1}\right)$ & $E_{l}\left(\mathrm{~mm} \cdot \mathrm{a}^{-1}\right)$ & $Q_{a}\left(\mathrm{~m}^{3} \cdot \mathrm{a}^{-1}\right)$ \\
\hline Value & $\arctan 50$ & 45 & $5 \times 10^{-4}$ & $5 \times 10^{-4}$ & 1052 & 1531 & 20 & 1800.2 & 327.1 & 78931.25 \\
\hline
\end{tabular}

water level and the low water level, respectively, reach a stable level. It is worth noting that the high water level has a significant upper limit, which means that the reservoir has an upper limit water level. The actual model of reservoir replenishment and loss is close to the intermediate condition (Figures 9-11). It can be considered that the upstream reservoir of DE without outlet has an upper limit water level under the ideal condition of fixed annual water inflow.

The water levels of the 20th year of the calculation results are extracted and compared with the measured water levels, with the results shown in Table 3 . The calculated high water level of each condition is larger than the measured historical high water level of the reservoir. This is mainly related to the deterministic method used in the paper, including model establishment and parameter selection. However, the calculated results are consistent with the measured data in some aspects.

3.3. Frequency Flood Check. For a flood discharge structure, it is necessary to consider the flood discharge capacity of different return periods [40, 41]. In addition, an earth-rock dam will fill to a certain level of equilibrium during normal years and will not fail, but it may fail with abnormal traffic in the following years [42, 44]. As water levels in extreme climatic conditions must be taken into account, a flood check was conducted on the reservoir to study the overtopping risk of the $\mathrm{DE}$ and the effect of frequency flood on the upper limit water level mechanism.

The total amount of design flood is calculated by the inference formula method based on local rainfall. The calculation formulas are

$$
\begin{aligned}
& W_{P}=\gamma H_{P} F, \\
& H_{P}=K_{P} \overline{H_{24}},
\end{aligned}
$$

where $W^{P}$ is the total design flood in $10^{4} \mathrm{~m}^{3}, \gamma$ is the runoff coefficient of total frequency flood without dimension, $F$ is the catchment area, in $\mathrm{km}^{2}, H_{P}$ is the 24-hour rainfall at the central point of the basin with a frequency of $p$ in $\mathrm{mm}, K_{P}$ is the modulus coefficient with a frequency of $p$, and $\overline{H_{24}}$ is the mean value of the maximum 24 -hour rainstorm in the basin, which is obtained from the local hydrological manual. It refers to the multiyear average.

The highway where the DE is located is a secondary highway. According to the relevant codes [45], the design

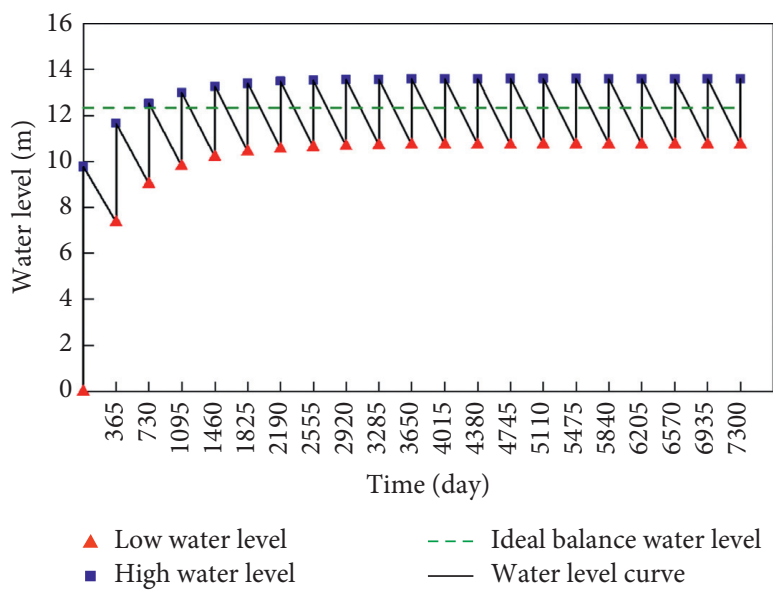

FIGURE 7: Water level fluctuation when an instantaneous rainfall enters the reservoir under the extreme conditions each year.

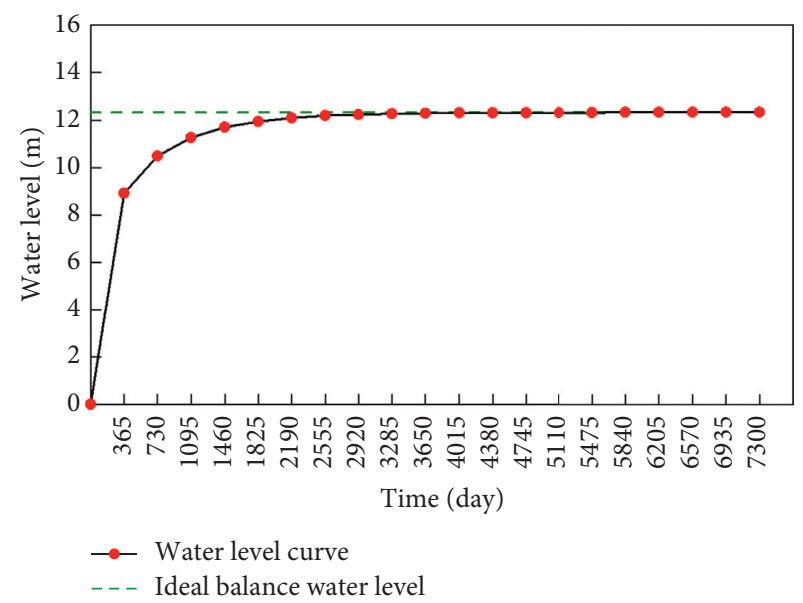

Figure 8: Water level fluctuation when continuous rainfall enters the reservoir under the extreme conditions all the time.

flood frequency is $1 / 50$. As specified in the Atlas of Statistical Parameters of Rainstorms in China, it is concluded that $\overline{H_{24}}=45 \mathrm{~mm}, K_{P}=2.42$, and $\gamma=0.5$. By using equations (17) and (18), $W_{P}$ is calculated as $10908.14 \mathrm{~m}^{3}$. This value is far less than the annual inflow of the reservoir $\left(78931.25 \mathrm{~m}^{3}\right)$.

When the reservoir is in the condition of Figure $5(\mathrm{~d})$, it is assumed that the frequency flood occurs during the flood season of the 10th year. When the water level reaches a high water level, it encounters a frequency flood to simulate the 


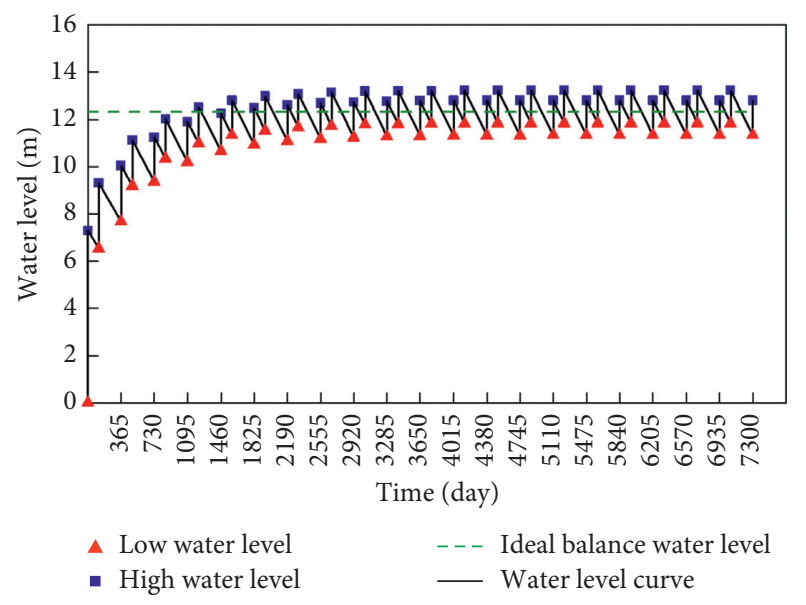

FIGURE 9: Water level fluctuation when two instantaneous rainfalls enter the reservoir under the intermediate conditions each year.

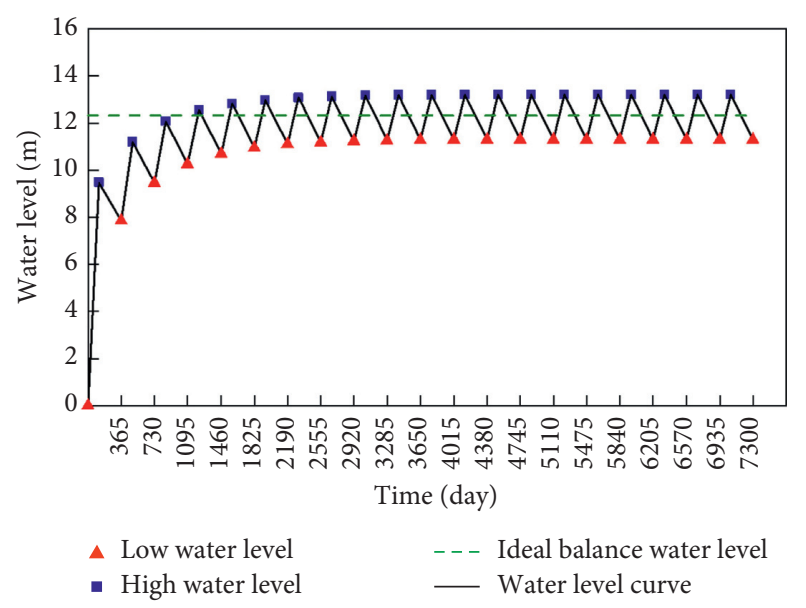

FIGURE 10: Water level fluctuation when one continuous rainfalls enters the reservoir under the intermediate conditions each year.

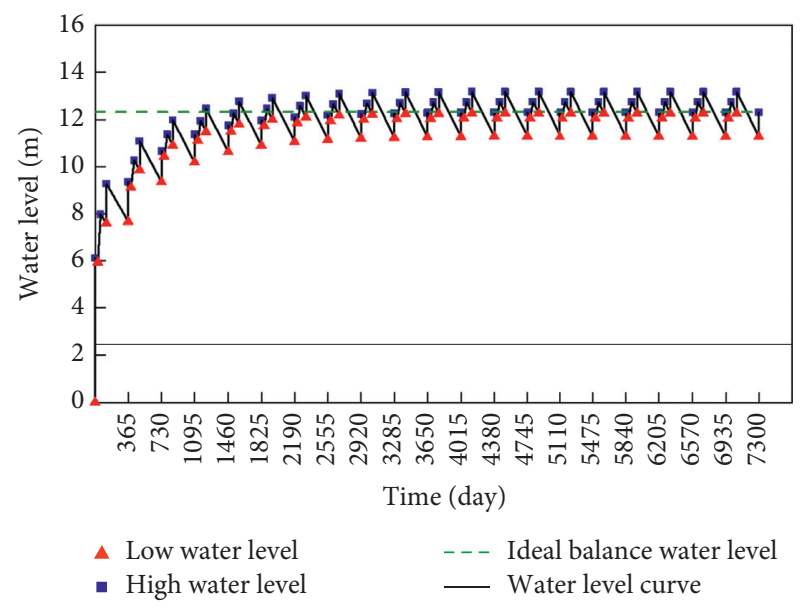

FIgURE 11: Water level fluctuation of mixed rainfalls entering reservoir under intermediate conditions each year. most unfavorable situation. The obtained water level fluctuation chart is provided in Figure 12. It can be seen that even if the frequency flood occurs during the design period, the water level does not rise much, and it will gradually decrease when the water enters the reservoir normally in the following years. Furthermore, the water level eventually stabilizes and returns to equilibrium (the upper limit water level returns to the original stable value). The water level is finally constrained by the upper limit water level mechanism which shows that frequency flood does not affect the upper limit water level mechanism of the upstream reservoir of DE. Even in the worst-case scenario of a 50-year return-period flood, water level rise will not exceed $14 \mathrm{~m}$, which is far less than the culvert bottom height of the dam embankment $(18.40 \mathrm{~m})$. The embankment will not encounter overtopping within its design life.

\section{Engineering Significance}

4.1. Causes of the Upper Limit Water Level. A schematic diagram of the flow of upstream reservoirs and common reservoirs is provided in Figure 13. The upstream reservoir of the $\mathrm{DE}$ can be considered as a small reservoir, but it has its own characteristics. Compared with the sufficient amount of water in the common reservoir, the amount of water entering the upstream reservoir of the DE is small, and the only water source is rainwater. Contrasting with reservoirs that use spillways or discharge structures to regulate flood, the upstream reservoir of the DE is relatively closed and its only water loss is evaporation and leakage, except when the water level exceeds the bottom of the culverts. Coupled with the big upper and small bottom shape of the upstream reservoir of the DE, these three conditions combine to create the upper limit water level mechanism of the upstream reservoir.

The upstream reservoir of the DE has the shape of a big upper and small bottom. With the increase of water level, the reservoir water volume and the water area increases accordingly. Moreover, as the water level increases, the water level change caused by the same amount of water entering the reservoir is smaller, and corresponding to this, the amount of evaporation and leakage is larger [46, 47]. Therefore, the water level will not increase indefinitely and will instead reach an equilibrium level. When the replenishment rate and the loss rate are equal, the water level becomes the ideal balance water level. The equilibrium state is dynamic, and the water level will fluctuate above and below the ideal balance water level. When the replenishment amount is greater than the loss amount in a certain period of time, the water level rises, and when the replenishment amount is less than the loss amount in a certain period of time, the water level drops. Moreover, an upper limit of water level will exist, without considering the limit of $\mathrm{DE}$ height and drainage facilities. Even if the reservoir encounters frequent floods, the water level will not rise dramatically as frequency flood water accounts for only a small part of the annual inflow of reservoir water. The water level is finally constrained by the upper limit water level mechanism. 
TABLE 3: Summary and comparison of water level values for the 20th year.

\begin{tabular}{|c|c|c|c|c|c|c|c|c|c|}
\hline Conditions & $\begin{array}{l}\text { Supplement } \\
\text { and loss mode }\end{array}$ & $\begin{array}{l}\text { Water level } \\
\text { fluctuation }\end{array}$ & $\begin{array}{c}\text { Ideal } \\
\text { balance } \\
\text { water level } \\
\text { (m) }\end{array}$ & $\begin{array}{l}\text { Low } \\
\text { water } \\
\text { level } \\
(\mathrm{m})\end{array}$ & $\begin{array}{l}\text { High } \\
\text { water } \\
\text { level } \\
(\mathrm{m})\end{array}$ & $\begin{array}{c}\text { Difference } \\
\text { between high } \\
\text { and low water } \\
\text { levels }(\mathrm{m})\end{array}$ & $\begin{array}{l}\text { Historical } \\
\text { highest } \\
\text { water level } \\
\text { (m) }\end{array}$ & $\begin{array}{c}\text { Culvert } \\
\text { bottom } \\
\text { height } \\
(\mathrm{m})\end{array}$ & $\begin{array}{c}\text { Measured } \\
\text { difference } \\
\text { between high } \\
\text { and low water } \\
\text { levels (m) }\end{array}$ \\
\hline \multirow{2}{*}{$\begin{array}{l}\text { Extreme } \\
\text { conditions }\end{array}$} & Figure 5(b) & Figure 7 & \multirow{5}{*}{12.32} & 10.73 & 13.59 & 2.86 & \multirow{5}{*}{12.87} & \multirow{5}{*}{18.40} & \multirow{5}{*}{1.72} \\
\hline & Figure $5(c)$ & Figure 8 & & - & - & - & & & \\
\hline \multirow{3}{*}{$\begin{array}{l}\text { Intermediate } \\
\text { conditions }\end{array}$} & Figure $5(\mathrm{~d})$ & Figure 9 & & 11.33 & 13.24 & 1.91 & & & \\
\hline & Figure $5(\mathrm{e})$ & Figure 10 & & 11.30 & 13.21 & 1.91 & & & \\
\hline & Figure $5(f)$ & Figure 11 & & 11.28 & 13.18 & 1.90 & & & \\
\hline
\end{tabular}

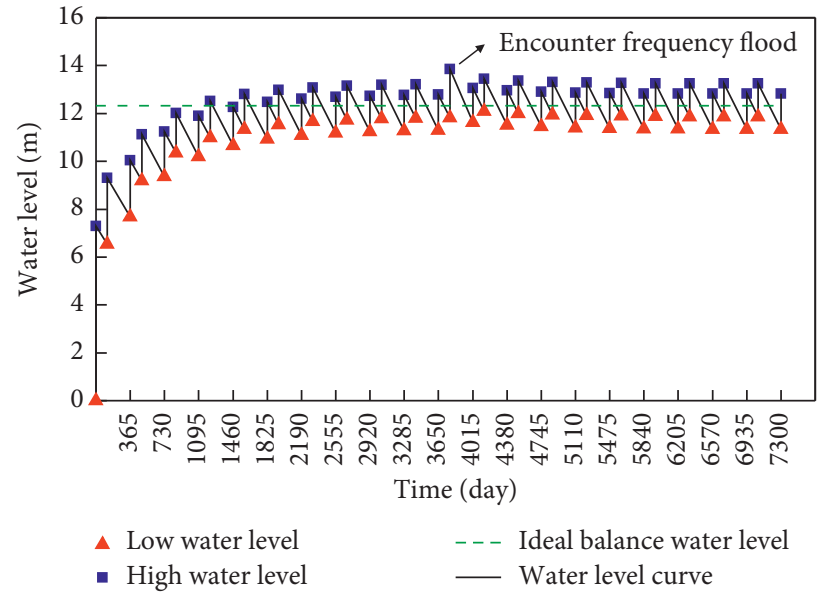

FIGURE 12: Water level fluctuation of the reservoir encountering frequency flood in the 10th year.

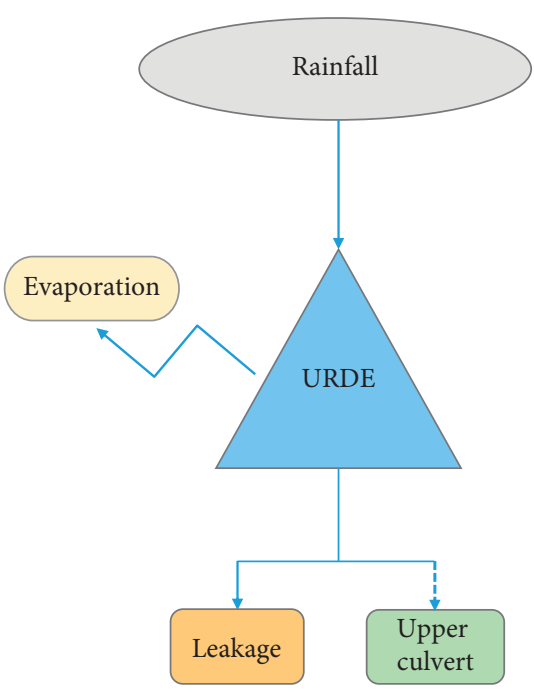

(a)

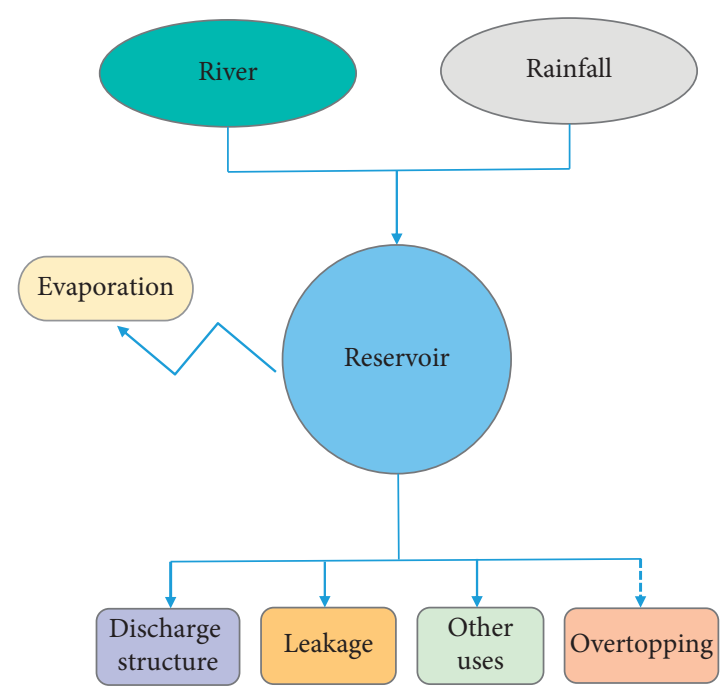

(b)

FIGURE 13: (a) Water replenishment and loss in the upstream reservoir of dam embankment (URDE); (b) water replenishment and loss in common reservoirs. 


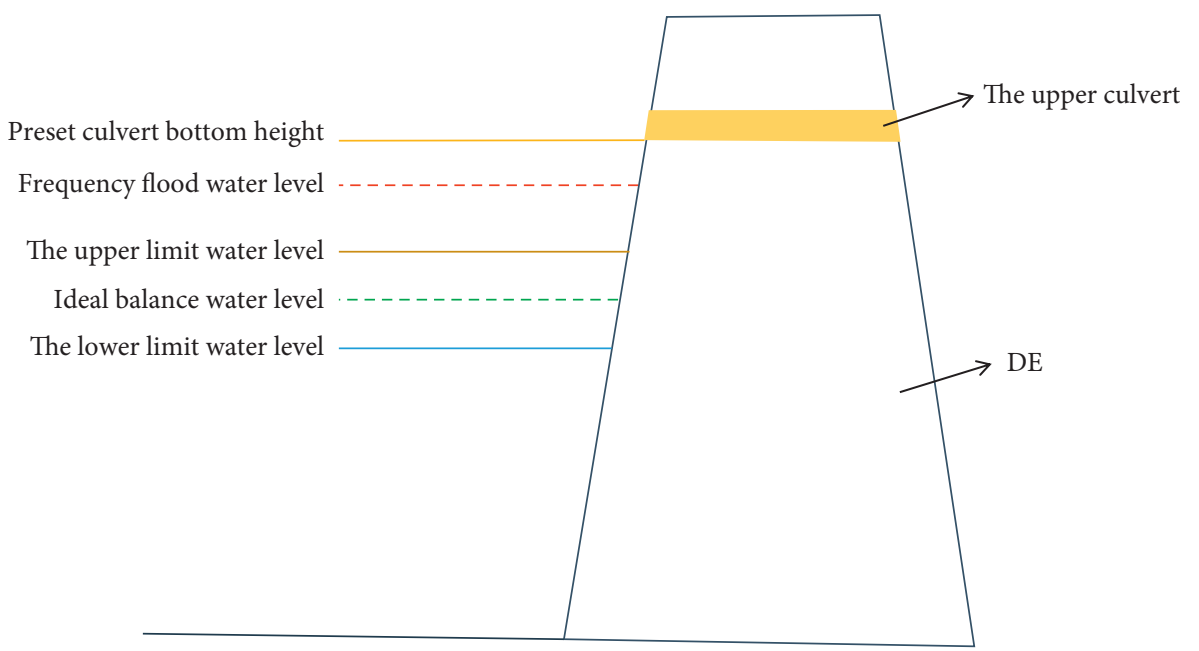

FIGURE 14: Engineering significance of upper limit water level.

TABLE 4: Criterion for the setting of the upper culvert.

$V_{Z}>W_{P}$

No upper culvert should be built or suspended

$V_{Z} \leq W_{P}$

Upper culvert should be constructed

4.2. Engineering Significance. For an upstream reservoir of DE (the actual height is generally $20-60 \mathrm{~m}$ ), the parameter value will be different from that selected in this paper. However, as long as the calculated upper limit water level is within the allowable range of embankment height, the upper limit water level mechanism still exists. This means that the reservoir water level will fluctuate up and down near the ideal balance water level and there is a clear upper limit water level (Figure 14).

As shown in Figure 14, the upper limit water level is the maximum of the normal water level, thus the flood detention capacity is the smallest. This is conservative and feasible for the preliminary design of the flood discharge capacity of the upper culvert. In the design of the upper culvert, the formula of flood discharge capacity is introduced:

$$
q_{p}=Q_{P}\left(1-\frac{V_{Z}}{W_{P}}\right),
$$

where $q_{p}$ is the flood discharge flow, $Q_{P}$ is the design flood peak flow, $V_{Z}$ is the flood detention capacity, and $W_{P}$ is the design flood volume.

Flood storage capacity $V_{Z}$ can be obtained by using the upper limit water level and preset culvert bottom height through the water level-reservoir capacity curve. By calculating the value of $q_{p}$, the setting conditions of the upper culverts can be determined. The criterion conditions for the setting of the upper culvert are listed in Table 4.

At present, most of the DE culverts are idle, and this can be divided into two situations. In the first case, the culverts should not be constructed or are suspended in the design life. In the second scenario, it is necessary to set up the culverts, but the flood discharge capacity of the culverts has not been fully observed as frequent floods have not yet occurred.
Recognizing the mechanism of the upper limit water level and further obtaining the criteria conditions for the setting of the upper culvert provide important reference significance for the design of DE culverts. This is of great significance to improve the existing design of DE culverts, and can reduce the construction and maintenance costs of culvert construction.

\section{Conclusion}

This paper is a preliminary study, and the conclusions are also preliminary results. On the basis of the existing research, this study derived the upper limit water level mechanism in the upstream reservoir of the DE. The criterion for the setting of the upper culvert on the DE was proposed through the mechanism of upper limit water level.

As a unique product of the Loess Plateau, the location of the $\mathrm{DE}$ is determined by route selection of the highway. The area where the DE is located has large evaporation, small rainfall (the only water source), and large leakage. This kind of area will not be used as a site for dams in water conservancy and hydropower, and the dam will not have a natural upper limit water level. However, this unique environment just created the upper limit water level mechanism in the upstream reservoir of a DE. The conclusion of the upper limit water level mechanism provides a basis for the setting conditions of the upper culverts. Through the setting criterions, it can be determined that a part of the upper culverts on the DE should not be constructed or postponed during the design period. It will provide managers and DE engineers with a more comprehensive understanding of the necessity of the upper culvert setting, and will help to reduce project and maintenance costs. This work also contributes to increased understanding of the principle of water balance. 
As a small reservoir, the upstream reservoir of the DE plays an active role in the local community. It is worth mentioning that the upstream reservoir is a derivative of the highway, which is usually built in arid and sem-arid gully areas of the Loess Plateau. Such reservoirs have reduced soil erosion, strengthened groundwater resources, improved local climate, and preserved water resources in the region. More importantly, they mitigate the negative effects of local climate change and provide a useful reference for other arid areas throughout the world. As the benefits of small reservoirs are increasingly recognized, the upper limit water level mechanism detailed in this paper is expected to provide useful reference for the designers and managers of small reservoirs in other areas.

However, the research contains some limitations. Firstly, the established reservoir model was based on a DE spanning the trapezoidal gully on the Loess Plateau, and a disparity remains between the reservoir model and the actual reservoir. Secondly, the simulated water replenishment and loss mode is relatively simple without fully considering the randomness of annual rainfall, evaporation, and leakage, and only several extreme conditions of rainfalls were simulated.

In future research, the calculation results should more accurately reflect the actual situation by improving the model and optimizing the reservoir replenishment loss model. More consideration should be given to the discharge capacity of different return periods. Moreover, the applicable judgment conditions for the setting of the upper culvert of the embankment should be further explored based on the upper limit water level mechanism.

\section{Data Availability}

The data used to support the findings of this study are available from the corresponding author upon request.

\section{Conflicts of Interest}

The authors declare that there are no conflicts of interest regarding the publication of this paper.

\section{Acknowledgments}

This work was supported by the Science and Technology Project of Shaanxi Transportation Department (no. 20160023K).

\section{References}

[1] X. Ma and H. Jiang, "Combined tectonics and climate forcing for the widespread aeolian dust accumulation in the Chinese Loess Plateau since the early late Miocene," International Geology Review, vol. 57, no. 14, pp. 1861-1876, 2015.

[2] P. Zhou, A. Wen, X. Zhang, and X. He, "Soil conservation and sustainable eco-environment in the Loess Plateau of China," Environmental Earth Sciences, vol. 68, pp. 633-639, 2012.

[3] G. Zhao, X. Mu, Z. Wen, F. Wang, and P. Gao, "Soil erosion, conservation, and eco-environment changes in the Loess Plateau of China," Land Degradation \& Development, vol. 24, no. 5, pp. 499-510, 2013.
[4] B. Fu, Y. Liu, Y. Lü, C. He, Y. Zeng, and B. Wu, "Assessing the soil erosion control service of ecosystems change in the Loess Plateau of China," Ecological Complexity, vol. 8, no. 4, pp. 284-293, 2011.

[5] S. A. N. Lousada, Hydrology, Water Resources and Environment: Theorical Classes, pp. 1-220, Universidade da Madeira, Funchal, Portugal, 2019.

[6] P. Tian, G. Zhao, X. Mu, F. Wang, P. Gao, and Z. Mi, "Check dam identification using multisource data and their effects on streamflow and sediment load in a Chinese Loess Plateau catchment," Journal of Applied Remote Sensing, vol. 7, no. 1, p. $073697,2013$.

[7] Y. D. Xu, B. J. Fu, and C. S. He, "Assessing the hydrological effect of the check dams in the Loess Plateau, China, by model simulations," Hydrology and Earth System Sciences, vol. 17, no. 6, pp. 2185-2193, 2013.

[8] G. Agoramoorthy, S. Chaudhary, P. Chinnasamy, and M. J. Hsu, "Harvesting river water through small dams promote positive environmental impact," Environmental Monitoring and Assessment, vol. 188, no. 11, p. 645, 2016.

[9] J. González-Romero, M. E. Lucas-Borja, P. A. Plaza-Álvarez, J. Sagra, D. Moya, and J. De Las Heras, "Temporal effects of post-fire check dam construction on soil functionality in SE Spain," Science of the Total Environment, vol. 642, pp. 117124, 2018.

[10] J. Nyssen, W. Clymans, K. Descheemaeker et al., "Impact of soil and water conservation measures on catchment hydrological response-a case in north Ethiopia," Hydrological Processes, vol. 24, no. 13, pp. 1880-1895, 2010.

[11] V. O. Polyakov, M. H. Nichols, M. P. McClaran, and M. A. Nearing, "Effect of check dams on runoff, sediment yield, and retention on small semiarid watersheds," Journal of Soil and Water Conservation, vol. 69, no. 5, pp. 414-421, 2014.

[12] X. Qin, P. Ni, and M. Zhou, "Improved analytical solution of vertical pressure on top of induced trench rigid culverts," Geosynthetics International, vol. 24, no. 6, pp. 615-624, 2017.

[13] Q. Ma, Z. Ku, H. Xiao, and B. Hu, "Calculation of earth pressure on culvert underlying flexible subgrade," Results in Physics, vol. 12, pp. 535-542, 2019.

[14] T. Liu, Y. Xie, Z. H. Feng, Y. B. Luo, K. Wang, and W. Xu, "Better understanding the failure modes of tunnels excavated in the boulder-cobble mixed strata by distinct element method," Engineering Failure Analysis, vol. 116, pp. 535-542, Article ID 104712, 2020.

[15] Z. Zhou, J. Lei, S. Zhu, S. Qiao, and H. Zhang, "The formation mechanism and influence factors of highway waterfall ice: a preliminary study," Sustainability, vol. 11, no. 15, p. 4059, 2019.

[16] O. S. Oshati, A. J. Valsangkar, and A. B. Schriver, "Performance of two cast-in-place box culverts under high embankments," Canadian Geotechnical Journal, vol. 49, no. 12, pp. 1331-1346, 2012.

[17] Z. J. Zhou, Z. P. Zhang, and C. R. Chen, "Application of load transfer method for bored pile in loess area," European Journal of Environmental and Civil Engineering, vol. 12, 2020.

[18] M. Moradi, H. Valipour, and S. Foster, "Reserve of strength in inverted U-shaped RC culverts: effect of backfill on ultimate load capacity and fatigue life," Journal of Bridge Engineering, vol. 21, no. 2, p. 10, 2016.

[19] B. Chen and L. Sun, "Performance of a reinforced concrete box culvert installed in trapezoidal trenches," Journal of Bridge Engineering, vol. 19, no. 1, pp. 120-130, 2014.

[20] Y. Sawamura, K. Kishida, and M. Kimura, "Evaluation of dynamic behavior of culverts and embankments through 
centrifuge model tests and a numerical analysis," Computer Methods and Recent Advances in Geomechanics, Taylor \& Francis Group, London, UK, 2014.

[21] Z. J. Zhou, F. Xu, J. T. Lei et al., "Experimental study of the influence of different hole-forming methods on the bearing characteristics of post-grouting pile in loess areas," Transportation Geotechnics, vol. 27, p. 100423, 2020.

[22] T. Xu, Z. Zhou, R. Yan et al., "Real-time monitoring method for layered compaction quality of loess subgrade based on hydraulic compactor reinforcement," Sensors, vol. 20, no. 15, p. $4288,2020$.

[23] Z. Zhou, J. Lei, S. Shi, and T. Liu, "Seismic response of aeolian sand high embankment slopes in shaking table tests," Applied Sciences, vol. 9, no. 8, pp. 1677-1719, 2019.

[24] J. M. Norman, R. J. Houghtalen, and W. J. Johnston, Hydraulic Design of Highway Culverts, The National Technical Information Service, Springfield, VA, USA, 2001.

[25] CCCC Highway Consultants Co. Ltd, General Specifications for Design of Highway Bridges and Culverts, JTG D60-2015, Vol. 17, China Communications Press Co.,Ltd., Beijing, China, 2015.

[26] W. Gao, X. Zhi, Z. Tang, X. Yang, and X. Zhao, "Calculation method of water storage increment of culvert and attached flood-discharge device in dam-embankment," China Journal of Highway and Transport, vol. 24, pp. 29-35, 2011.

[27] S. Xu, Q. Zou, X. She, J. Feng, and L. Shi, "Pool level analysis of highway loess dam embankment," Journal of Traffic and Transportation Engineering (China), vol. 12, pp. 13-19, 2012.

[28] S. Xu, X. She, S. Lei, G. Ren, and H. Xue, "Study on flood limit level of highway loess dam-like embankment," China Journal of Highway and Transport, vol. 28, no. 3, pp. 11-19, 2015.

[29] S. Xu, S. Zhang, and Z. Zhou, "Design and calculation method of highway loess dam-like embankment flood limit level and culvert flood discharge capacity," China Journal of Highway and Transport, vol. 31, pp. 26-33, 2018.

[30] J. Huang, O. Hinokidani, H. Yasuda, C. S. P. Ojha, Y. Kajikawa, and S. Li, "Effects of the check dam system on water redistribution in the Chinese Loess Plateau," Journal of Hydrologic Engineering, vol. 18, no. 8, pp. 929-940, 2013.

[31] M. E. Lucas-Borja, D. A. Zema, M. D. Hinojosa Guzman et al., "Exploring the influence of vegetation cover, sediment storage capacity and channel dimensions on stone check dam conditions and effectiveness in a large regulated river in México," Ecological Engineering, vol. 122, pp. 39-47, 2018.

[32] V. Díaz, J. Mongil, and J. Navarro, “Topographical surveying for improved assessment of sediment retention in check dams applied to a Mediterranean badlands restoration site (Central Spain)," Journal of Soils and Sediments, vol. 14, no. 12, pp. 2045-2056, 2014.

[33] L. Cavaleri, G. Ciraolo, M. F. Ferrotto, G. La Loggia, C. Lo Re, and G. Manno, "Masonry structures subjected to tsunami loads: modeling issues and application to a case study," Structures, vol. 27, pp. 2192-2207, 2020.

[34] L. Cavaleri, F. Di Trapani, and M. F. Ferrotto, "A new hybrid procedure for the definition of seismic vulnerability in Mediterranean cross-border urban areas," Natural Hazards, vol. 86, no. 2, pp. 517-541, 2017.

[35] J. Stolle, T. Takabatake, T. Mikami et al., "Experimental investigation of debris-induced loading in tsunami-like flood events," Geosciences, vol. 7, no. 3, p. 74, 2017.

[36] Yellow River Engineering Consulting Co.,Ltd., Code of Engineering Hydrogeology Investigation for Water Resources and Hydropower, SL373-2007, China Water \& Power Press, Beijing, China, 2007.
[37] M. Kummu, P. J. Ward, H. de Moel, and O. Varis, "Is physical water scarcity a new phenomenon? Global assessment of water shortage over the last two millennia," Environmental Research Letters, vol. 5, no. 3, pp. 034006-10, 2010.

[38] Z. Li, F.-L. Zheng, W.-Z. Liu, and D. C. Flanagan, "Spatial distribution and temporal trends of extreme temperature and precipitation events on the Loess Plateau of China during 1961-2007," Quaternary International, vol. 226, no. 1-2, pp. 92-100, 2010.

[39] S. Fatichi, V. Y. Ivanov, and E. Caporali, "Simulation of future climate scenarios with a weather generator," Advances in Water Resources, vol. 34, no. 4, pp. 448-467, 2011.

[40] F. Lempérière, "Dams and floods," Engineering, vol. 3, no. 1, pp. 144-149, 2017.

[41] M. Polemio and P. Lollino, "Failure of infrastructure embankments induced by flooding and seepage: a neglected source of hazard," Natural Hazards and Earth System Sciences, vol. 11, no. 12, pp. 3383-3396, 2011.

[42] J. E. Costa and R. L. Schuster, "The formation and failure of natural dams," Geological Society of America Bulletin, vol. 100, no. 7, pp. 1054-1068, 1988.

[43] Y. Y. Li, J. Linghu, Z. T. Li et al., "Comparison of durability and mechanism between sprayed concrete and ordinary concrete at different erosion age," Journal of materials in civil engineering, vol. 26, 2020.

[44] X. Xu, H. Zhang, and O. Zhang, "Development of check-dam systems in gullies on the Loess Plateau, China," Environmental Science \& Policy, vol. 7, no. 2, pp. 79-86, 2004.

[45] China Construction Standard Highway Committee, Technical Standard of Highway Engineering, JTG B01-2014, China Communications Press, Beijing, China, 2014.

[46] H. Wu, Y. J. Zhong, W. Xu, W. Shi, X. H. Shi, and T. Liu, "Experimental investigation of ground and air temperature fields of a cold-region road tunnel in NW China," Advances in Civil Engineering, vol. 2020, Article ID 4732490, 12 pages, 2020.

[47] D. Wisser, S. Frolking, E. M. Douglas, B. M. Fekete, A. H. Schumann, and C. J. Vörösmarty, "The significance of local water resources captured in small reservoirs for crop production-a global-scale analysis," Journal of Hydrology, vol. 384, no. 3-4, pp. 264-275, 2010. 